\title{
Evaluating English as a Second Language: A Naturalistic Model
}

Gail V. Barrington

The article describes a program evaluation study of a special English as a Second Language program conducted by the Calgary Board of Education entitled CORE-ESL. This program was developed to meet the needs of a group of 18 to 21 year olds with a severe gap in their schooling due to political upheaval and war. The program was funded for a one-year period by a local foundation which requested that an external evaluation be conducted. The study was designed as a naturalistic model involving five stages of data collection and participant involvement. These five stages are described and study recommendations and outcomes are outlined. A composite student profile, developed in the study, is appended to the article.

The program evaluation model outlined by Stake (1967) stressed two evaluative activities, description and judgment; description of program objectives, environments, activities, and accomplishments; judgment of program congruence with goals and external standards. Recently, however, more responsive evaluation models, such as the naturalistic model described by Guba and Lincoln (1981), have begun to acknowledge the differing needs and concerns of the several audiences for which any evaluation is conducted. Guba and Lincoln $(1981 ; 57-8)$ suggest that a naturalistic evaluator acknowledges the multiple realities or perspectives that exist in a study, "like the layers of an onion." All layers must be viewed together to create a three-dimensional construction of the truth. More recently, Guba and Lincoln (1985) have refined their concept of naturalistic evaluation, classifying it as a "fourth generation" evaluation model (as compared with first generation evaluation characterized by measurement, second generation by description, and third generation by judgment). Fourth generation evaluators acknowledge not only that different interest groups and audiences have different perspectives, but that they hold different values. The evaluator becomes a negotiator and change agent, moving from group to group, in an emergent, collaborative quest for definitions of issues, and later, for solutions.

The English as a Second language (ESL) evaluation study described below used such fourth generation techniques as polling multiple realities, checking and re-checking value perceptions, involving relevant interest 
groups in the definition of specific issues, and negotiating solutions with those most likely to be affected by them.

\section{THE PROGRAM}

An external evaluation of the ESL services provided by the Calgary Board of Education (Barrington, 1982) identified a group of students in the senior high schools whose needs were not being met by the regular ESL program. In the 1981-82 school year, 25\% of the Calgary board's ESL high school students between the ages of 16 and 18 had only four to six years of schooling. Many had been out of school for a number of years due to political upheaval, war, internment, and family dislocation. Most were from southeast Asia. ESL classes at the high school level operated on the assumption that students were functioning from a solid base of literacy and thinking skills in their first language. The adolescents identified with such an extensive educational gap were not likely to benefit fully from traditional ESL instruction nor to integrate with the regular high school program.

As a result, ESL administrators developed a program, entitled COREESL, to address the needs of this special group of students and requested funding from a private foundation. Due to this special funding arrangement, the program had to be run out of the Continuing Education Department and thus was aimed at a slightly older population, the 18 to 21 age group. It was hoped that demonstrated success with this group might lead in the future to a similar project for high school-aged students using regular funding.

The goals of CORE-ESL were identified as follows:
a) To teach aural/oral English language skills
b) To orient the students to Canadian life and culture
c) To teach basic English literacy skills
d) To teach basic survival math skills
e) To provide career counselling during the course and follow-up after its completion
f) To refer students to other agencies and programs when appropriate.

The program was to offer one year of full-time instruction and was to be staffed by three ESL teachers. Students were to be selected on the basis of the following criteria:
a) Age (i.e. 18-21 age group)
b) Newly arrived to Canada
c) Unemployed
d) No other appropriate placement available 
It was anticipated that these students would have an acute educational gap, or might indeed be illiterate in their first language; would have no academic focus; would need to make great social and psychological adjustments to Canadian life; would have unrealistic educational goals in view of their educational backgrounds; and would have financial difficulties which hindered them from taking a vailable courses. It was judged that this program would meet a need not addressed by existing adult ESL classes which were part-time, charged fees, and did not include upgrading, job-oriented skills, and counselling.

The foundation provided a grant for $\$ 112,968$ for a one-year program with the stipulation that an external evaluation of the project be conducted.

\section{THE EVALUATION}

An external evaluator was hired on a contract basis by the Calgary Board of Education. Administrators requested that the evaluation be of a descriptive nature so that the final report could be used to solicit further funding, should the program be judged successful. They planned to request financial support the following year from a number of sources including the foundation itself, the board, and several government agencies. The breadth of the audience to which the final report must appeal necessitated what they termed a "non-statistical" approach to the evaluation. Apart from this stipulation, the administrators were open to suggestions from the evaluator as to how the study should proceed.

After several preliminary meetings and a tour of the site, the evaluator judged that several considerations should be kept in mind in the development of a study design; specifically: 1) that secure funding was the desired outcome of the study; 2) that a variety of interest groups needed to be involved in the study, not only students, teachers, and program administrators, but also advisory committee members and senior Board of Education administrators to develop greater program visibility and encourage ownership of the program; and 3) that a "human interest" approach including student case studies would best appeal to foundation and board members.

Based on these considerations, the following evaluation goals were established in consultation with the advisory committee:

1. To develop descriptive data about CORE-ESL students

2. To determine the amount of student growth (September 1984 May 1985)

3. To explore attitudes of students, teachers, administrators, advisory committee members and other interest groups towards 


\section{CORE-ESL}

4. Based on data collected, to make recommendations about the future of the CORE-ESL program.

The design of the study was a naturalistic model involving five stages of data collection and participant involvement (Consult Table 1.) It acknowledged the differing perceptions of the program held by different participants and interest groups and stressed an interactive, collaborative approach to defining issues and developing solutions. At the critical point of generating recommendations, the evaluator acted as a negotiator between interest groups to promote issue resolution. It must be noted, however, that at all times the evaluator relied on accepted evaluation methodology and due to her external position was able to act as an impartial facilitator.

\section{Stage 1}

In order to develop student case studies and a composite student profile, a number of data collection techniques were employed. The evaluator spent several days on site observing both classes and informal student interaction at breaks and lunch hour. A sample of student files was analyzed to determine the types of data they held. Such documents as admission forms, admission interview notes, biographical data, pre-test results and teacher comments were available in these files.

Based upon this information, a draft Student Profile document was developed by the evaluator. The ESL teachers were asked to review the profile to suggest omissions or changes they felt important in order to clarify the data to be collected. Following their review, the profile was revised and the final data collection document included the following components:

A. Descriptive Data:
Age
Sex
Country of Origin
Ethnic Group
Interim Status (i.e. prior to coming to Canada)
Length of Time in Canada
Family Arrangements
Employment Status
Health Problems
Previous Education
Skill Level - Program Entrance

B. Educational Growth: 
Table 1

Evaluation Design: CORE-ESL Evaluation Study

Calgary Board of Education, 1984-85

\section{STAGE 1:}

STUDENTS

Document analysis

Observation

Interviews

Pre-/Post-tests

Teacher Observation

STAGE 2:

TEACHERS

Topic list

Interviews

Informal discussions

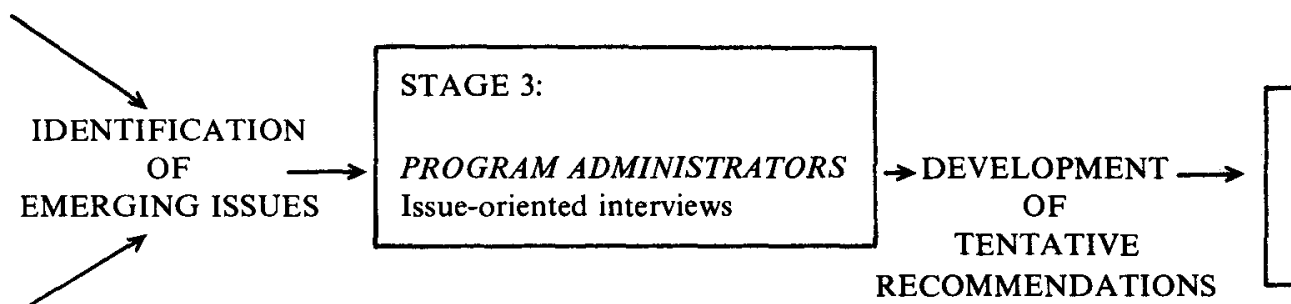

STAGE 5:

TEACHERS

PROGRAM ADMINISTRATORS

Review of draft report

\section{RECOMMENDATIONS}

STAGE 4:

INTEREST GROUPS

Issue-specific interviews

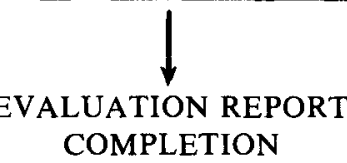


Skill Level - Program Exit

Identified Learning Problems

\section{Personal Growth:}

Social Adjustment

Behavioral Adjustment

Future Goals

General Comments about Program's

Impact (Students and Teachers)

Most of the descriptive data were immediately available from student files, although in some cases teachers were consulted for missing information. Baseline educational information was also available including previous education and students' skill levels in English and Mathematics at program entrance. Entrance attitudes and behaviours were also noted in the files and provided a baseline for personal growth measurement.

However, the rest of the data could not be collected until as near to the project's end as possible. Due to time constraints placed on the study by the foundation, 'exit' levels of attainment were measured in April and did not reflect student's final achievement in the academic year. Thus, although most data regarding students were collected in the initial stage of the study, the Student Profiles were not completed until near the end of the project. At that time, students were interviewed in English by the evaluator to provide their insight into their own personal growth and to obtain their impressions of the program's impact. Teachers' comments were also solicited regarding educational and personal growth, and they were asked to comment on students' interview data to provide a veracity check on student-reported attitudes. (The evaluator requested this check to counteract any bias her position of authority may have elicited from students respectful of authority figures). Finally post-test scores were collected.

The completed Student Profiles were analyzed through the tabulation of descriptive data, the analysis of pre- and post-test scores through the use of the t-test, and the analysis of qualitative data through the use of summarization and the development of categories. Results were prepared for an appendix to the final report, and a composite Student Profile was prepared in descriptive language for inclusion in the report (Consult Appendix 1.). To provide breadth to the profile and to counteract any possibility of stereotyping, two case studies of actual project students were written by the teachers and included in the report as well.

\section{Stage 2}

To gain an accurate reading of the ESL teachers' perceptions of the program and its appropriateness to student needs, three data collection 
techniques were employed. First of all a list of possible interview types was presented to teachers for their consideration. Based upon their suggestions, the list was revised and developed into an interview format which comprised the following topics:

1. General background of teachers

2. Teacher perception of program appropriateness to student neeeds

3. Teacher perception of adequacy of program support to teacher needs

4. Program strengths and needs

5. Program goal review

6. Conclusions about the program

Each item consisted of both a Likert-type scale and an open-ended question.

The completed CORE-ESL Teacher Interviews were analyzed for mean scores, and responses and comments were analyzed for content. A summary of the interview data was prepared and appended to the final report.

\section{Stage 3}

Based on the data collected in Stages 1 and 2, a series of emerging issues was identified such as program location, program length and program management. In Stage 3, these issues were discussed with program administrators in lengthy non-structured interviews with the objective of identifying possible solutions, or as occurred in some cases, identifying roadblocks to possible solutions. Based on their input and reactions to the identified issues, the evaluator developed a list of tentative recommendations.

\section{Stage 4}

To determine the feasibility of proposed recommendations, a series of ten interviews was scheduled with various senior administrators, advisory committee members and other interest group representatives (e.g. Race Relations Officer, Calgary Police Force). The interviews focused on specific issues of relevance to the particular individuals involved. For example, two senior administrators of the Board of Education were interviewed to determine under whose jurisdiction the program more appropriately belonged; advisory committe members were interviewed regarding an expanded role for the advisory committee; a curriculum supervisor was interviewed about the possibility of including vocational activities in the program, etc. During this process the evaluator was aware of the need to heighten the program's visibility and to forewarn adminis- 
trators about the approaching need to find alternate funding for another year, should the program be judged successful. In this way the evaluator acted as a negotiator and change agent, negotiating solutions which were acceptable to all groups, laying the groundwork for future decision making which the program would require. Finally a revised list of recommendations was prepared, based on the input of all the interest groups which had been polled.

\section{Stage 5}

A draft report was prepared which included a program description, the identification of program strengths and program needs, a review of program goals, and conclusions and recommendations. The draft was circulated to the teachers and program administrators for their final reactions and comments. Generally, they were satisfied with the degree of comprehensiveness of the report and they acknowledged that the recommendations were both appropriate and feasible. Minor revisions were made to the draft and the final report was prepared and presented to the advisory committee. The program administrators forwarded copies to both the foundation and the trustees of the Calgary Board of Education.

Overall, the report concluded that CORE-ESL was very successful in addressing "the academic, social and emotional needs" of these high-risk, special-needs ESL students (Barrington, 1985: 31).

Fifteen recommendations for future action were proposed, including, most importantly, that the program should continue to be offered, that it should be expanded to a maximum of two years of instruction, that a reliable funding base be established, and that program management be clarified in terms of lines of authority and responsibility. Other recommendations addressed such things as the need for a facility change, a half-time administrator and a culturally-sensitive counsellor, a need to broaden entrance criteria, improve screening and diagnosis, clarify program goals, expand the advisory committee's role, provide in-service training for teachers, and take advantage of school board resources such as shops, labs and physical education facilities.

\section{Study Outcomes}

The evaluation study was favourably received by foundation members whose support of its findings led them to agree to provide financial support for an additional six-month period (i.e. September 1985 - February 1986), thus allowing the Board of Education time to locate secure funding. Board administrators acted upon the study's recommendations by expanding the program to a two year format while continuing to 
encourage students to exit as soon as possible, by providing administrative and counselling support, by clarifying program goals and by incorporating access to school board facilities such as shops and a typing room. Further, they piloted a twin project at the senior high level which incorporated many of the positive aspects of the CORE program including its full-time nature. This second project, begun in September 1985, is attempting to meet the needs of the high school-aged, special-needs ESL student population identified in the original system-wide evaluation (Barrington, 1982).

\section{DISCUSSION}

The naturalistic evaluation model employed in this evaluation study enabled the evaluator to probe issues and perceptions of reality with increasing specificity as the study progressed from stage to stage. Fourth generation evaluation techniques were employed such as checking and re-checking perceptions, and involving interest groups in issue identification and solution definition. The evaluator expanded the evaluation role to include not only the traditional three evaluative activities of measurement (descriptive statistics, t-tests), description (composite student profile and case studies), and judgment (identification of issues, development of initial list of recommendations), but also employed the fourth generation activity of negotiation (teacher interview format, issue-specific interviews, revisions of draft report) in the evaluation process. To meet the needs of a variety of audiences and interest groups and to foster workable outcomes, an emergent, collaborative design engendered a responsive evaluation study which had a positive impact upon the program under review.

\section{NOTES}

1. This is a revised version of a paper originally presented at the Joint Meeting of the Canadian Evaluation Society, Evaluation Network, and Evaluation Research Society, Toronto, Ontario, October 19, 1985.

2. Copies of English as a Second Language-CORE-ESL: An Evaluation By Gail V. Barrington, Ph.D. can be obtained by contacting this address:

Ms. Jan MacDougall

Supervisor, K-12 ESL Program

Riverside Bungalow

711 - 2nd Avenue N.E.

Calgary, Alberta

T2E 0G3 


\section{REFERENCES}

Barrington, G.V. (1982). English as a second language: An evaluation of the Calgary Board of Education ESL services-Grades 1-12. Edmonton: Planning Services, Alberta Education.

. (1985). English as a second language-CORE-ESL: An evaluation.

Calgary: Program Evaluation Section, Office of the Chief Superintendend, Calgary Board of Education.

Guba, E.G. \& Lincoln, Y.S. (1981). Effective evaluation: Improving the usefulness of evaluation results through responsive and naturalistic approaches. San Francisco: Jossey-Bass.

. (1985). The countenances of fourth-generation evaluation: Description, judgment, and negotiation. Paper presented to the joint meeting of the Canadian Evaluation Society, Evaluation Network, and Evaluation Research Society, Toronto, Ont.

Smith, W. (1985, September 3-6). The Vietnamese: 5 years after. The Calgary Herald.

Stake, R.E. (1967). The countenance of educational evaluation. Teacher's College Record, 68, 523-540.

\section{THE AUTHOR}

Gail V. Barrington holds a B.A. from McGill University and an M.A. from Carleton University, both in English Literature, and a Ph.D. in Educational Administration from the University of Alberta. She holds permanent teaching certificates in both Quebec and Alberta and has taught for nearly twenty years at all levels from elementary to post-secondary in such areas as English as a second language, reading, writing skills, literature and educational administration. Currently she is director and principal consultant for GAIL V. BARRINGTON \& ASSOCIATES, a consulting firm which specializes in program evaluation and research studies in the areas of education and training. 


\section{APPENDIX 1 \\ Composite Student Profile CORE-ESL Evaluation Study \\ Calgary Board of Education, 1985}

The typical CORE-ESL student is a male Vietnamese of ethnic Chinese descent between the ages of 18 and 19. It is likely that he came directly to Canada from Vietnam, although eight of his classmates spent several years in refugee camps before arriving here. His brother sponsored him as well as his parents and other brothers and sisters, but some family members still remain in Vietnam and loneliness is a daily spectre. Although his brother likely has a full-time job, his own English is not very good and so his job is probably a low-paying one. However, all the adults in the family may not be employed, and money is their major concern. Unlike many mainstream Canadian 18-year-olds, the CORE-ESL student is expected to contribute financially toward the good of the whole family. If he does not have a part-time job cleaning offices like many of his classmates, he wants to do so and yet he is caught in a dilemma: if he doesn't continue studying English, his chances for advancement will be minimal when he does go to work; if he gets a job now to help support his family, he will not be able to devote himself to his studies and so his English will be poor. Almost half of his classmates work 16 to 25 hours a week in the evening, leaving them little time to study and causing them to be tired in class. These are heavy responsibilities to wrestle with considering that he tends not to have a future orientation to his thinking. Life up until now has been so unpredictable that there has been no point in planning ahead and so he has had some problems learning to focus his activities and set goals for himself. Over the course of eight months in CORE, he has made remarkable progress. He has learned to discuss his problems with his teacher, he has started to feel that maybe life in Canada will turn out well and that maybe a career will be possible. For now, though, he wants to continue studying his English in CORE for another year and then move on to regular adult education courses. In fact, his math has improved so much, he will probably be ready for Math 13 in the fall. 
